\title{
Spirituality and well being among elders: differences between elders with heart failure and those without heart failure
}

\author{
Mary T Quinn Griffin' \\ Yi-Hui Lee ${ }^{2}$ \\ Ali Salman' \\ Yaewon Seo' \\ Patricia A Marin ${ }^{3}$ \\ Randall C Starling ${ }^{3}$ \\ Joyce J Fitzpatrick' \\ 'Frances Payne Bolton School of \\ Nursing Case Western Reserve \\ University Cleveland, $\mathrm{OH} ;{ }^{2}$ College \\ of Nursing and Health Wright State \\ University Dayton, $\mathrm{OH} ;{ }^{3} \mathrm{Cleveland}$ \\ Clinic, Cleveland, Ohio
}

\begin{abstract}
Heart failure is a chronic debilitating disease that affects all aspects of a person's life, including physical, mental and spiritual dimensions. The associations among these dimensions, and the relationship to overall health status, have not been clearly identified. The purpose of this quantitative, descriptive study was to explore differences between spirituality, depressive symptoms, and quality of life among elders with and without heart failure. A total of 44 elders with heart failure and 40 non-heart failure elders completed several questionnaires including: The Daily Spiritual Experiences Scale (DSES), Spirituality Index of Well-Being (SIWB), Center for Epidemiologic Studies Depression Scale (CES-D), and SF-12 ${ }^{\text {TM }}$ Health Survey. There were significant differences in the groups on gender and ethnicity; thus these variables were controlled in the analyses related to the dependent variables. After controlling for gender and ethnicity, there were significant differences in the physical component of quality of life and spiritual well-being. The heart failure patients had significantly lower physical quality of life but more spiritual well-being than the non-heart failure patients. There were no significant differences in daily spiritual experiences, mental component of quality of life, and depressive symptoms between the two groups.
\end{abstract}

Keywords: spiritual experience, spiritual well-being, heart failure, depressive symptoms, quality of life, elders

Heart failure is one of the most threatening and potentially disabling diseases. It is a chronic health problem that is typically associated with marked functional limitation and compromised quality of life (QOL) for the affected individuals and their families. It also may be coupled with clinically relevant psychological impairments such as depression, anxiety, uncertainty, and anger. In the US, there are approximately 5 million individuals living with heart failure (NHLBI 2006) with 5\% aged 60 to 69 years and $10 \%$ over the age of 70 years. There are 550,000 new patients diagnosed with heart failure every year in the US, predominately males (NHLBI 2006).

Several studies have explored depression in patients with heart failure. Patients with heart failure were more likely to have a higher rate of depression (24\%) than those in a control group (9.7\%) (Havranek et al 1999). Depressive symptoms were found in $42 \%$ of ambulatory patients with heart failure (Skotzko et al 2000). Researchers also have found that depressed heart failure patients were at increased risk of mortality in comparison to their counterparts who did not experience depressive symptoms along with heart failure (Rozzini et al 2002).

Spirituality has been conceptualized as including an individual's transcendent relationship with a higher being or with the universe and has been positively linked to hope, coping, and religiosity (O'Neill and Kenny 1998). It has been found to be 
particularly important among older adults, and positively linked to self-appraised good health among elders (Daaleman and Frey 2004).

Previous researchers have studied spirituality in heart failure patients. Spirituality and quality of life were studied among 58 persons with heart failure being treated medically or by transplant (Beery et al 2002). The average age of the participants ranged from 22 to 68 years with the majority being male. The sample included $90 \%$ European American and $10 \%$ African American. Gender differences were not significant with regard to spirituality. Results indicated that spiritual well-being as measured by the Spiritual Well Being Scale (SWB) which included religious and existential well-being was significantly related to global quality of life, and disease-specific (heart failure) quality of life. The SF-36 was used to measure the health-related quality of life. The mental composite score was significantly related to spiritual, religious, and existential well-being whereas the physical composite score of the SF-36 was not significantly related. Disease specific quality of life was measured using the Minnesota Living with Heart Failure Questionnaire. The emotional and physical symptoms on this scale were significantly inversely related to spiritual, religious, and existential well-being. Berry et al suggested that spirituality may affect the emotional/mental response to a disease rather than influencing the symptoms of a specific disease such as heart failure.

Researchers interviewed 87 patients from two out-patient heart failure clinics to ascertain the role of spirituality in the adjustment to their illness (Westlake and Dracup 2001). The sample was made up of $68.9 \%$ males with an average age of 56.1 years $(+12.9)$. Of the 87 respondents, $70.1 \%$ were Caucasian, $14.9 \%$ Latino and $6.9 \%$ African American; 24.1\% were New York Heart Association (NYHA) classes I and II and 75.9\% were classes III and IV. In the findings regarding spirituality, patients described regret over past behaviors and lifestyles, the search for meaning within the present experience, and hope for the future and reclaiming of optimism.

Westlake and colleagues (2002) studied spirituality (as measured by the Spiritual Perspective Scale) and health related quality of life (HRQOL) as measured by the SF-36 in patients with heart failure being evaluated for cardiac transplantation. The majority of the participants (85\%) were either NYHA class II or III and 12\% were class IV. Of the 61 participants, $74 \%$ were male; the average age was 57 years. The majority of participants were Caucasian (84\%), with $15 \%$ Hispanic and 2\% African American. Subjects reported a moderate level of spirituality; women were more spiritual than men. There was no significant relationship between spirituality and HRQOL.

Hardin and colleagues (2003) studied 29 patients with heart failure to determine the relationship between spirituality and New York Heart Association (NYHA) heart failure functional classes I through IV. Seventy percent of the patients were men; the average age was 72.76 years. Eighteen of the 29 patients were NYHA Stage I and II; 11 were stages III and IV. Patients with advanced stages of heart failure had significantly lower scores on the spiritual involvement and belief scale (SIBS) than patients in earlier stages of heart failure. Patients with late stage illness agreed significantly with two of the statements on the SIBS compared to those with Stages I and II. These statements indicated that prayers do not really change what happens, and that they would probably not reexamine their spiritual beliefs. Hardin et al suggested that patients with late stage heart failure may be more concerned with physiological needs as opposed to spirituality. There was no significant difference between men and women on the SIBS scores.

Research results regarding spirituality among heart failure patients are inconclusive; no two studies used the same measures of spirituality. No previous research is available comparing patients with heart failure to those without heart failure. Researchers who studied spirituality and quality of life, while concluding that spiritual factors appear to be related to overall physical health, found no relationship to mental components of health. Thoresen and Harris (2002) recommended additional research, particularly attention to psychological factors. This present study was an attempt to address one dimension of psychological health (depressive symptoms) and its relationship to spirituality in heart failure and non-heart failure patients.

\section{Methods}

The purpose of this study was to explore differences between spirituality (including spiritual experiences and spiritual well-being), depressive symptoms, and quality of life among elders with and without heart failure. This study was conducted at a large urban, tertiary referral teaching hospital. Patients were recruited from the heart failure out-patient department of the main hospital and from a family practice clinic from the regional clinics. Institutional Review Board approval was obtained from the patient care facility and from the university.

A convenience sample of heart failure (HF) patients and non-HF patients who attended either the heart failure clinic, 
for the HF group, or a family practice clinic for the non-HF group was obtained. Both clinics were part of a large urban, tertiary referral teaching hospital. Data were collected in early 2006. The inclusion criteria for this study were that all the patients were; (a) 65years or older, (b) able to speak and read English, In addition, the HF patients were NYHA classification II to IV. The exclusion criteria for the study were (a) patients who were cognitively impaired; and (b) no diagnosis of HF among the non-HF group.

The physicians and nurse practitioner identified potential subjects and invited eligible patients to participate in the study. The researchers explained the study to all subjects and informed consent was obtained prior to completion of the questionnaires. The questionnaires were self-administered. The researcher assessed the NYHA classification of the individuals in the HF group. Following data collection, each subject was given $\$ 5$ as a token of appreciation.

\section{Instruments}

Spirituality was measured using two instruments, the daily spiritual experiences scale (DSES) which measures spiritual experiences, and the spirituality index of well-being (SIWB) which measures spiritual well-being. These two spirituality instruments were chosen as they measured a broad range of spiritual dimensions, and have strong psychometric properties. Depressive symptoms were measured by the Center for epidemiologic studies depression scale (CES-D). Quality of life was measured by the SF-12 ${ }^{\text {TM }}$ Health Survey. Both the CES-D and the SF-12 have been used with older adults. The SF-12 was selected rather than the longer SF-36 as time for completion was a consideration.

The DSES consists of 16 items in a six-point Likerttype format. Each item asks the respondent to choose how often they experience the spirituality concept referred to in the statement. Content validity was supported by the use of qualitative interviews and focus groups, as well as a review of current spirituality scales. Reliability and validity data were obtained through two studies of the 16 item instrument. The authors reported that each of the 16 items significantly loaded on one of two factors within the tool. In the two studies, the internal consistency reliability was .94 and .95. With an average completion time of less than two minutes for the entire scale, it is very practical for both clinical and research administration (Underwood and Teresi 2002).

The spirituality index of well-being (SIWB) is a 12 item scale to measure the effect of spirituality on subjective wellbeing (Daaleman and Frey 2004). Items 1 to 6 address selfefficacy while items 7 to 12 address life scheme. A multi-site cross-sectional survey with 523 adult outpatients at primary care clinics in the Midwest was conducted to determine the scale psychometrics. Study results reported a Cronbach's $\alpha$ of .91, indicating good internal consistency. Each of the 6 item subscales showed good reliability, $\alpha=.86$ for selfefficacy and $\alpha=.89$ for life scheme. Test retest reliability for the total scale was .79 and .77 and .86 for each of the subscales respectively. Factor analysis showed that the two factor model accounted for $56 \%$ of the total variance; selfefficacy, factor 1 , accounted for $27.2 \%$ of the variance while life scheme, factor 2 , accounted for the remaining $28.6 \%$ (Daaleman and Frey 2004).

The CES-D was developed to measure symptoms of depression in community populations. It was designed to measure four dimensions of depressive symptoms: depressed affect, positive affect, somatic and retarded activity, and interpersonal (Radloff 1977). The CES-D consists of 20 items that measure depressed mood, feelings of worthlessness, loss of appetite, poor concentration, sleep disturbance, and feelings of helplessness. It takes approximately 5 minutes to complete. The CES-D is a 4-point rating scale with a time frame for reporting symptoms in the past week. The possible range of total scores varies between 0 and 60, with a higher score indicating more depressive symptoms. A score of 16 or higher is designated as a standard cutoff point to determine the presence of significant depressive symptoms. The Cronbach's alpha reliability coefficient for the 20 items of the CES-D was .85 for the general population and test-retest reliability values ranged from .51 to .67 (Radloff 1977). The CES-D has been reported to have good internal consistency (Cronbach's alpha) with a range of .87 to .92 in the elderly (Davidson et al 1994; Williamson and Schulz 1992).

SF-12 ${ }^{\text {TM }}$ Health Survey (Qualitymetric 2006) is a valid and reliable self-administered, 12-item scale developed from the SF-36 that measures the perceived health-related quality of life for eight concepts (physical functioning, role-physical, bodily pain, general health, vitality, social functioning, roleemotional, and mental health) of two major domains, that of physical and mental health. SF-12 has been used for measuring health status and monitoring health outcomes in both general and specific populations. The test-retest reliability was reported as .64 to .89 (Ware et al 1996), and validity was supported with a strong correlation $(r=0.94)$ with SF-36 (Hurst et al 1998).

\section{Results}

The sample consisted of 84 subjects, 44 with HF and 40 in the non-HF group. In the total sample and in both groups, the 
majority of the subjects were between 65 and 75 years old. More than $50 \%$ of the total sample was female. There was a significant difference in gender between the two groups; in the HF group, there were significantly more men $(n=30$, $68.2 \%)\left(\mathrm{X}^{2}=21.84, \mathrm{p}=.000\right)$. In the total sample, $78.6 \%$ were White/non Hispanic; $15.5 \%$ were Black/non Hispanic. All of the Black/non Hispanic subjects were in the HF group $\left.(\mathrm{n}=13,29.5 \%) ; \mathrm{X}^{2}=14.15, \mathrm{p}=0.003\right)$. Table 1 includes the demographic characteristics of the subjects.

Fifty percent $(\mathrm{n}=22)$ of the subjects in the HF group were classified as NYHA class II; 31.8\% were class III; and 18.3\% were class IV. These results are included in Table 2.

Means, standard deviations (SD), and ranges were computed for the dependent variables of spiritual experiences, spiritual well-being, quality of life (physical and mental), and depressive symptoms in the total sample, the HF group, and non-HF group. The HF group reported more daily spiritual experiences and more spiritual well-being than the non-HF
Table 2 NYHA functional class in the heart failure group $(\mathrm{N}=44)$

\begin{tabular}{lll}
\hline NYHA class & N & $\%$ \\
\hline II & 22 & 50.0 \\
III & 14 & 31.8 \\
IV & 8 & 18.3 \\
\hline
\end{tabular}

group. The HF group reported more depressive symptoms than the non-HF group. Physical and mental quality of life were lower in the HF group. These results are presented in Table 3.

As described above there were significant differences between the HF and non-HF groups on gender and ethnicity. Further analyses controlled for the effects of these two variables. Only two ethnic groups, White and Black, were included in these analyses. After controlling for gender and ethnicity, spiritual well-being and physical component of quality of life were significantly different between the HF groups and the non-HF group. The HF group had significantly

Table I Characteristics of the sample

\begin{tabular}{|c|c|c|c|}
\hline Characteristics & $\begin{array}{l}\text { Total }(n=84) \\
N(\%)\end{array}$ & $\begin{array}{l}\text { HF }(n=44) \\
N(\%)\end{array}$ & $\begin{array}{l}\text { Non HF }(n=40) \\
N(\%)\end{array}$ \\
\hline \multicolumn{4}{|l|}{ Gender } \\
\hline Male & $37(44.0)$ & $30(68.2)$ & $7(\mid 7.5)$ \\
\hline Female & $47(56.0)$ & $14(3 \mid .8)$ & $33(82.5)$ \\
\hline \multicolumn{4}{|l|}{ Race/Ethnicity } \\
\hline American Indian/Alaskan Native & $2(2.4)$ & $\mathrm{I}(2.3)$ & $\mathrm{I}(2.3)$ \\
\hline Black/Non Hispanic & $13(15.5)$ & $13(29.5)$ & \\
\hline Hispanic & $3(3.6)$ & I (2.3) & $2(5.0)$ \\
\hline White/Non-Hispanic & $66(78.6)$ & $29(65.9)$ & $37(92.5)$ \\
\hline \multicolumn{4}{|l|}{ Age } \\
\hline$>65-75$ & $51(60.7)$ & $27(6 \mid .4)$ & $24(60.0)$ \\
\hline $76-85$ & $29(34.5)$ & $14(3 \mid .8)$ & $15(37.5)$ \\
\hline$>86$ & $4(4.8)$ & $3(4.8)$ & $\mathrm{I}(2.5)$ \\
\hline \multicolumn{4}{|l|}{ Marital Status } \\
\hline Married & $53(63.1)$ & $29(65.9)$ & $24(60.0)$ \\
\hline Widowed & $20(23.8)$ & $9(20.5)$ & II (27.5) \\
\hline Single & II (13.2) & $6(13.7)$ & $5(12.5)$ \\
\hline \multicolumn{4}{|l|}{ Highest level of education } \\
\hline$\geq$ Some college & $48(57.2)$ & $26(59.2)$ & $22(52.5)$ \\
\hline 7 th grade to 12 th grade & $32(38.2)$ & $14(31.8)$ & $18(32.5)$ \\
\hline Less than 7 years of school & $3(3.6)$ & $3(6.8)$ & $\mathrm{I}(2.5)$ \\
\hline \multicolumn{4}{|l|}{ Joint annual income of your family? } \\
\hline Under $\$ 50,000$ & $46(54.8)$ & $27(61.4)$ & $19(47.5)$ \\
\hline$\$ 50,000$ to $\$ 74,999$ & $14(16.7)$ & $7(15.9)$ & $7(17.5)$ \\
\hline$\geq \$ 75,000$ & $12(14.4)$ & $6(13.5)$ & $6(15.0)$ \\
\hline \multicolumn{4}{|l|}{ Religion } \\
\hline Christian & $76(90.5)$ & $36(81.8)$ & $40(100.0)$ \\
\hline Judaism & $4(4.8)$ & $4(9.1)$ & \\
\hline Islam & $2(2.4)$ & $2(4.5)$ & \\
\hline No Religious Affiliation & $\mathrm{I}(\mathrm{I} .2)$ & $\mathrm{I}(2.3)$ & \\
\hline
\end{tabular}


Table 3 Descriptive statistics on main variables

\begin{tabular}{|c|c|c|c|c|c|c|c|c|c|}
\hline \multirow[t]{2}{*}{ Variables } & \multicolumn{3}{|c|}{ Total $(n=79)$} & \multicolumn{3}{|c|}{ HF $(n=42)$} & \multicolumn{3}{|c|}{ Non HF $(n=37)$} \\
\hline & $M$ & SD & Range & $M$ & SD & Range & $M$ & SD & Range \\
\hline Daily spiritual & 34.60 & 15.54 & 9.00 & 35.90 & 17.3 & 9.00 & 33.1 & 13.2 & 15.00 \\
\hline experiences & & & 84.00 & & 8 & 84.00 & I & 3 & 69.00 \\
\hline Quality of life _ & 37.77 & 12.55 & 15.03 & 31.58 & 9.48 & 15.03 & 44.6 & 12.0 & 15.89 \\
\hline physical & & & 62.95 & & & 49.62 & 3 & 3 & 62.95 \\
\hline Quality of life _ & 51.29 & 9.75 & 25.36 & 50.65 & 10.3 & 27.78 & 52.0 & 9.10 & 25.36 \\
\hline mental & & & 64.54 & & 7 & 64.54 & 0 & & 63.21 \\
\hline spiritual index & 46.81 & 9.56 & 18.00 & 43.29 & 10.3 & 18.00 & 50.7 & 6.76 & 36.00 \\
\hline of well being & & & 60.00 & & 9 & 60.00 & 0 & & 60.00 \\
\hline Depressive & 9.77 & 7.66 & .00 & 11.07 & 8.18 & 1.00 & 8.35 & 6.88 & .00 \\
\hline symptoms & & & 38.00 & & & 38.00 & & & 23.00 \\
\hline
\end{tabular}

more spiritual well-being than the non-HF group $(\mathrm{F}=5.48$, $\mathrm{p}=0.02$ ). These results are presented in Table 4 .

While controlling for gender and ethnicity, the physical component of quality of life in the HF group was significantly lower than that of the non-HF group $(F=13.14, p=0.001)$. These results are presented in Table 5 .

After controlling for gender and ethnicity, there were no significant differences in daily spiritual experiences, mental component of quality of life, and depressive symptoms between the HF and non-HF groups.

\section{Discussion}

The overall percentage of males in the sample was $44 \%$. However, $68.2 \%$ of the HF group was male compared to $17.5 \%$ in the non-HF group. This finding is comparable to similar studies. Westlake and Dracup (2001) had 68.9\% males from two heart failure clinics in their study. Hardin et al (2003) had 70\% males in their study of 29 heart failure patients. Also heart disease is more common or at least diagnosed more frequently in men rather than women. Almost all (92.5\%) of the non-HF group were White/non-Hispanic. This can be accounted for as the family practice clinic was situated in a predominately white neighborhood. In the heart failure group, 29.5\% were Black/non Hispanic. The present study has a larger percentage of Black subjects compared to any of the previous studies of HF patients. In the study conducted by Westlake and Dracup, 70\% of the sample was Caucasian while 7\% was African American. Beery et al (2002) had a predominately Caucasian sample as $90 \%$ were European American and 10\% African American. Westlake et al (2002) had a sample with Caucasian (84\%), 15\% Hispanic, and 2\% African American when they investigated quality of life in HF patients.

In this study, in the HF group, 50\% were class II NYHA and $50 \%$ were Classes III and IV combined. However, as the total HF group included only 44 patients, inter-group comparisons were not made on any of the main variables. Westlake and Dracup (2001) had two-thirds of their sample in classes III and IV heart failure. In the Westlake et al's (2002) study, the majority of patients being evaluated for cardiac transplantation were either NYHA class II or III.

Spiritual Well-Being was higher in the HF group than the non-HF group, even after controlling for gender and ethnicity. Previously researchers have identified spiritual dimensions among heart failure patients at different stages of their illness. This present study is the first to compare spirituality among $\mathrm{HF}$ patients and non-HF patients. This finding of higher spiritual well-being may be related to the illness experience. It is of note that there were no differences in daily spiritual experiences once gender and ethnicity were controlled.

On the SF-12, the physical component scores were lower in the HF group. This is not an unexpected finding

Table 4 comparison in spiritual well-being between the HF group and non HF group after controlling for gender and ethnicity

\begin{tabular}{|c|c|c|c|c|c|}
\hline & $\begin{array}{l}\text { Type III } \\
\text { Sum of squares }\end{array}$ & df & Mean square & F test & Significance \\
\hline Corrected model & 1325.62 & 3 & 441.87 & 5.73 & 0.00 \\
\hline Intercept & 3348.35 & I & 3348.35 & 43.42 & 0.00 \\
\hline Gender & .31 & I & 0.31 & 0.00 & 0.95 \\
\hline Ethnic & 255.92 & l & 255.92 & 3.32 & 0.07 \\
\hline Group & 422.74 & I & 422.74 & 5.48 & 0.02 \\
\hline Error & 5706.49 & 74 & 77.12 & & \\
\hline Total & 177927.00 & 78 & & & \\
\hline
\end{tabular}


Table 5 Comparison in physical component of quality of life between the HF group and non HF group after controlling for gender and ethnicity

\begin{tabular}{|c|c|c|c|c|c|}
\hline & $\begin{array}{l}\text { Type III } \\
\text { Sum of squares }\end{array}$ & df & Mean square & F test & Significance \\
\hline Corrected model & 3473.29 & 3 & 1157.76 & 9.91 & 0.00 \\
\hline Intercept & 1925.04 & 1 & 1925.04 & 16.47 & 0.00 \\
\hline Gender & 55.45 & 1 & 55.45 & 0.47 & 0.49 \\
\hline Ethnic & II3.56 & I & 113.56 & 0.97 & 0.33 \\
\hline Group & 1536.35 & $\mathrm{I}$ & 1536.36 & 13.14 & 0.00 \\
\hline Error & 8649.40 & 74 & I 16.89 & & \\
\hline Total & 123407.68 & 78 & & & \\
\hline
\end{tabular}

as these patients are likely to have more physical symptoms than the non-HF group. However, one limitation of this study is that co-morbidities or medications were not measured in either group. There were no differences between the two groups for the mental composite scores once gender and ethnicity were controlled. A previous study found that the mental composite score was significantly related to spiritual, religious, and existential wellbeing while the physical composite score was not related (Beery et al 2002). In addition, there were no differences in depressive symptoms after controlling for gender and ethnicity. In previous research, patients with HF had high rates of depression and depressive symptoms (Havranek et al 1999; Skotzko et al 2000).

In summary, this study extends previous research on spirituality and well being among elders. Controlling for the effects of gender and ethnicity in this sample, differences between elders with HF and those without HF were found on spiritual well-being and physical quality of life. Several measures of spirituality were used in previous studies. Also, previous studies and this study included predominately Christian Caucasian subjects. The current study has the largest percentage of Blacks with heart failure, thus adding to the literature. Future research is needed to further clarify dimensions of spirituality, including spiritual well-being and spiritual experiences and their relationship to quality of life in older persons. Also, it is recommended that future studies include persons from different cultural and ethnic backgrounds. This study and previous studies were of heart failure patients who were outpatients. For comparison purposes, future research should address heart failure patients who are hospitalized as well as those who are outpatients.

\section{References}

Beery TA, Baas LS, Fowler C, et al. 2002. Spirituality in persons with heart failure. Journal of Holistic Nursing, 20:5-30.

Daaleman TP, Frey BB. 2004. The spirituality index of well-being: A new instrument for health-related quality of life. Annals of Family Medicine, 2:499-503.

Davidson H, Feldman PH, Crawford S. 1994. Measuring depressive symptoms in the frail elderly. Journal of Gerontology, 49:159-164.

Hardin SR, Hussey L, Steele L. 2003. Spirituality as integrality among chronic health failure patients: a pilot study. Visions, 11:43-53.

Havranek EP, Ware MG, Lowes BD. 1999. Prevalence of depression in congestive heart failure. American Journal of Cardiology, 84:348-50.

Hurst NP, Ruta DA, Kind P. 1998. Comparison of the MOS short form-12 (SF-12) health status questionnaire with the SF-36 in patients with rheumatoid arthritis. British Journal of Rheumatology, 37:862-9.

King DE, Bushwick B. 1994. Beliefs and attitudes of hospital inpatients about faith healing and prayer. Journal of Family Medicine, 39:349-52.

Luskin F. 2000. Review of the effect of spiritual and religious factors on mortality and morbidity with a focus on cardiovascular and pulmonary disease. Journal of Cardiopulmonary Rehabilitation, 20:8-15.

NHLBI (2006). Retrieved September 28, 2006 from http://www.nhlbi.nih. gov/health/dci/Diseases/Hf/HF_WhatIs.html.

O’Neill DP, Kenny E. 1998. Spirituality and chronic illness. Image: The Journal of Nursing Scholarship, 30, 275-80.

Qualitymetric (2006). Retrieved September 28, 2006 from http://www. qualitymetric.com/products/sfsurveys.aspx

Table 6 comparison in depressive symptoms between the HF group and non HF group after controlling for gender and ethnicity

\begin{tabular}{llllll}
\hline & $\begin{array}{l}\text { Type III } \\
\text { Sum of squares }\end{array}$ & df & Mean square & F test & Significance \\
\hline Corrected model & 261.95 & 3 & 87.32 & 1.519 & 0.22 \\
Intercept & 27.08 & 1 & 27.08 & 0.471 & 0.495 \\
Gender & 108.03 & 1 & 108.03 & 1.879 & 0.175 \\
Ethnic & 14.25 & 1 & 14.25 & 0.248 & 0.620 \\
Group & 241.83 & 1 & 241.83 & 4.21 & 0.044 \\
Error & 4195.84 & 74 & 57.48 & & \\
Total & 11802.00 & 78 & & & \\
\hline
\end{tabular}


Radloff LS. 1977. A CES-D scale: A self-report depression scale for research in the general population. Applied Psychological Measurement, $1: 385-401$.

Rozzini R, Sabatini T, Frisoni, GB, et al. 2002. Depression and major outcomes in older patients with heart failure. Archives of Internal Medicine, 162:362-4.

Skotzko CE, Krichten C, Zietowski G, et al. 2000. Depression is common and precludes accurate assessment of functional status in elderly patients with congestive heart failure. Journal of Cardiac Failure, 6:300-5.

Sloan RP, Bagiella E, Powell T. 1999. Religion, spirituality, and medicine. Lancet, 353:664-7.
Thoresen CE, Harris AH. 2002. Spirituality and health: what's the evidence and what's needed? Annals of Behavioral Medicine, 24:3-13.

Underwood LG, Teresi JA. 2002. The daily spiritual experience scale: development, theoretical description, reliability, exploratory factor analysis, and preliminary construct validity using health-related data. Annals of Behavioral Medicine, 24:22-33.

Ware J, Jr. Kosinski M, Keller SD. 1996. A 12-Item Short-Form Health Survey: construction of scales and preliminary tests of reliability and validity. Medical Care, 34:220-33. 
